\title{
ANALYSIS OF WOVEN FABRIC AT THE PLACE OF THE SEWN SEAM
}

\author{
Beti Rogina-Car', Ivana Schwarz², Stana Kovačević \\ ${ }^{1}$ University of Zagreb, Faculty of Textile Technology, Department for Clothing Technology, Prilaz baruna Filipovića 28a, \\ 10000 Zagreb, Croatia, phone: 38513712 574, fax: 35813712 599, e-mail: beti.rogina-car@ttf.hr \\ ${ }^{2}$ University of Zagreb, Faculty of Textile Technology, Department of Textile Design and Management, Prilaz baruna Filipovića 28a, \\ 10000 Zagreb, Croatia, phone: 38513712 574, fax: 35813712 599, e-mail: ivana.schwarz@ttf.hr; stana.kovacevic@ttf.hr \\ Corresponding author: Ph.D. Ivana Schwarz, ivana.schwarz@ttf.hr
}

\begin{abstract}
:
Key importance and the role of sewn seam in the woven fabric are presented. Fabric properties in the places joined with the sewn seam on which garment durability, applicability, appearance and quality depend are highlighted. Seam location is usually the weakest spot on the garment, especially when the great loads are present at these places. Mechanical properties of the sewn fabrics were investigated in different test conditions. The influence of the load on the sewn seam is analyzed in time intervals. Sample with seam have approximately $70 \%$ lower breaking properties (breaking force and elongation at break) than the sample without seam. By preloading the seam fabrics with $30 \%, 50 \%$ and $70 \%$ of elongation at break, for a 3-h period, the effect on mechanical properties were tested and the differences in pre-stretching intensity were observed. By conducting such test, it is expected that the fabric experience further degradation and that breaking properties further reduce, but the exact opposite occurred (breaking properties, by increasing the preload, increase even more), because of various material properties (structural fabric properties, raw material characteristics, seam characteristics).
\end{abstract}

\section{Keywords:}

sewn seam, mechanical properties, loading, wool/polyester woven fabric

\section{Introduction}

In order to meet end-use properties, fabric has to be formed into three-dimensional (3D) shape, which is why it is necessary to join single cutting patterns. Joining the fabric to form clothing or other item is usually made with sewn seams. In its characteristics, sewn seams usually meet the usability requirements of the textile item; the seam strength of the fabric is often lower in relation to seamless places. Durability of a textile item, especially which tolerates certain loads at the seams in use, usually depends on the strength and quality of the sewn seam, as well as on the properties of woven fabrics. Therefore, the seam is mostly the weakest part because it is located at the joint places where the load is greatest and most prominent [1-4]. Seam strength can be increased with thread fineness and stitch length. As sewing thread fineness depends on material fineness, needle size, and stitch length, it is not always possible to obtain a satisfactory seam to match in strength, quality, and appearance. Thread slippage in the sewing seam caused by stress depends not only on the thread and seam parameters but also on the structural fabric parameters and on the seam position on the garment or another textile item. This means that thread fineness, needle size, and stitch length depend on fabric weave, density, thickness, weight, and composition of the raw material [5-9]. By loading the textile material in use, it comes to elongation, especially in seam locations. Besides slippage, as a consequence of seam load, it is weakened and broken, especially in case of longer and greater loads and material weight. Therefore, quality and durability of a textile item is mostly limited with durability and quality of making a seam [10-14].

\subsection{The real problem in the application}

Clothing item in which the above-mentioned problem is the most common is jacket (suit). The specific body posture in sitting position, in which a man spends an increasing amount of time, leads to the appearance of tensions in textile material (jacket), which causes horizontal stress of material, thus, by sewn seam joined parts. These stresses affect mostly the middle vertical seam that joins two cutting parts of the back (Figure 1) and also arise on the seams of the back side and at the back part of the sleeve. Such body posture causes continuous long-term stresses, which affects the strength of the sewn seam as well as the quality and appearance of the garment.

An example of male jacket (suit) model given in Figure 2 shows the entire cutting pattern, indicating the areas of the cutting parts, which are joined with the seams and exposed to the highest stresses.

During cutting process, cutting parts are laid in the fabric warp direction, that is, joint places of cutting parts are directed specifically to the warp direction. The abovementioned stresses are, therefore, present in the fabric weft direction, which is taken into consideration in preparation of samples to implement the testing for the purpose of solving this issue. 


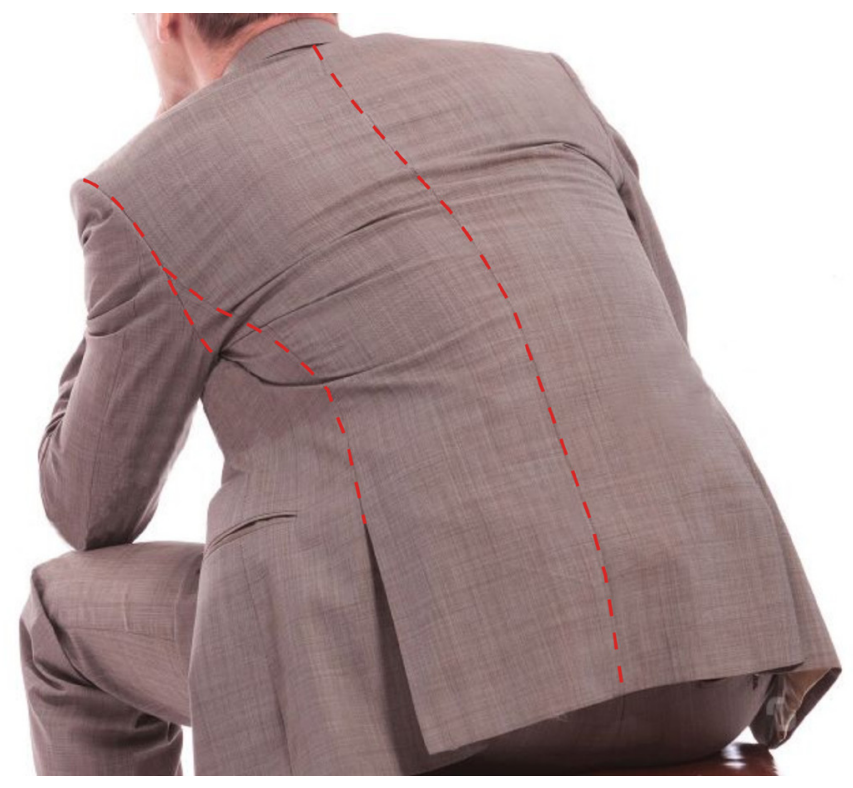

Figure 1. Representation of tensions of textile material (jacket) in sitting position

In order to determine the quality of clothing item, specifically jacket (suit), all parameters that have an effect on it were taken into consideration (properties of woven fabric, sewing thread, stitch length, fabric breaking properties, preload on breaking properties of the seam) and relevant tests were conducted.

Owing to the complexity of such research, there are a number of questions to be answered, such as is there a difference in the obtained results between standard and modified testing method of sewn seam strength; is there an influence of continuous mechanical load on the mechanical properties of seams and fabrics; what is the tendency of the breaking properties of the fabric on the seam because of the continuous mechanical load; and does the raw material composition affect the results of the continuous mechanical load of fabric?

Therefore, in this paper, the mentioned issues are explored with a new investigation approach of seam strength and fabric behavior on joined place, with the simulation of the realistic wearing conditions achieved by continuous mechanical load over a period of $3 \mathrm{~h}$.

\section{Experimental}

This investigation was conducted on woven fabric made of wool/ polyester (PES) in twill weave. Tensile force and elongation at break of seamless fabric samples in the warp and weft directions according to the standard HRN EN ISO 13934-1:2008 were tested. Likewise, seamed fabric samples were prepared by sewing in the warp direction, according to the standard HRN EN ISO 13935-1:2008. Fabric samples were sewn together with $100 \%$ PES thread, finesses 30 tex, with stitch density of 5 stitches/cm, using 1.01.01/301 type of the sewn seam, according to the standard ISO 4916, with needle thickness of $0.9 \mathrm{~mm}$. Stitch length and sewing thread fineness were chosen according to common practical values for the tested fabric samples. Breaking properties on sewn samples were tested in

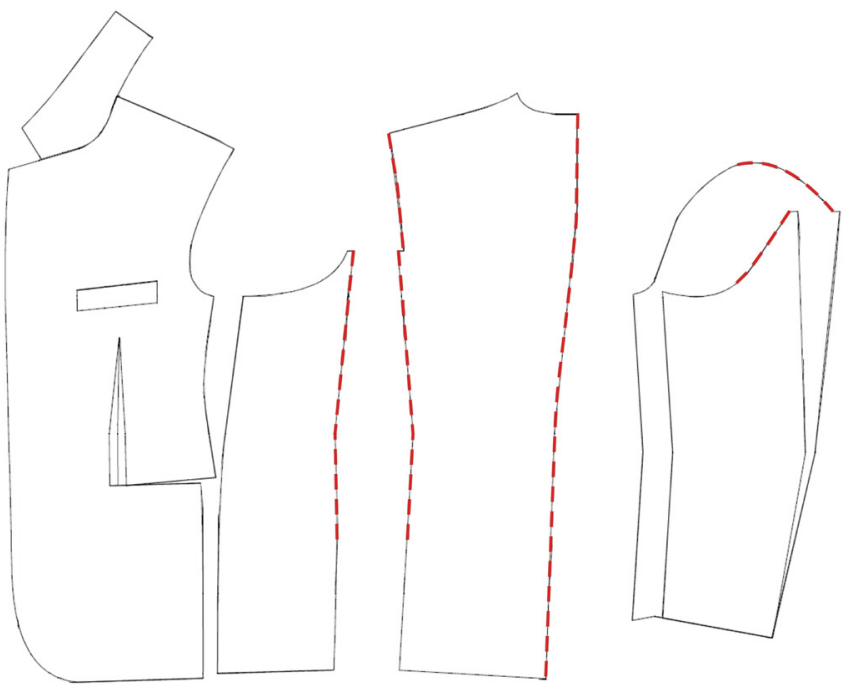

Figure 2. Cutting pattern of male jacket (suit) model with emphasis on the joint places characterized by the presence of greatest stress

weft direction (horizontal direction) without and with additional preload. Additional preload was defined with $30 \%, 50 \%$ and $70 \%$ of the average elongation at break of the sample tested without additional preload. After loading to a specific percentage of elongation, the samples were held in that position for a period of $3 \mathrm{~h}$ and, afterwards, loaded up to the break.

\section{Results and discussion}

Answers to the numerous questions and concerns that this research deals with, which represents the aim of this paper, are given in the following text.

Basic structure and mechanical parameters of tested woven fabrics are conducted and shown in Table 1. The breaking force of fabric tested in the warp direction is $1.386 \mathrm{~N}$, and that in the weft direction is $1.072 \mathrm{~N}$. Elongation at break followed the course of breaking forces and amounts $52.40 \%$ and $48.40 \%$ in the warp and weft directions, respectively. The reason for such large fabric elongation can be found in raw material content, more accurately wool, which contributes with its parameters to such a large elongation of fabric.

Seam appearance, strength, and durability are among the most important factors of garment quality. The load acting on the garment in use has the effect of deformations being the most prominent in the weakest and folding places where there is often a sewn seam (Figure 3).

Construction parameters of the fabric also affect the deformation of the garment as well as the properties of the sewn seam. Greater fabric density with a higher resistance to the interlacing points and contacts among threads produce a more durable fabric less sensitive to deformations.

It is well known that the joint parts are the weakest places in the material, as demonstrated also in this case. By joining cutting 
Table 1. Basic woven fabric parameters

\begin{tabular}{|c|c|c|c|}
\hline & & Warp & Weft \\
\hline \multicolumn{2}{|c|}{ Raw material composition } & \multicolumn{2}{|c|}{$45 \%$ wool / $55 \%$ polyester } \\
\hline \multicolumn{2}{|c|}{ Yarn count (tex) } & \multicolumn{2}{|c|}{$25 \times 2$} \\
\hline \multicolumn{2}{|c|}{ Weave } & \multicolumn{2}{|c|}{ Twill 2/2 } \\
\hline \multicolumn{2}{|c|}{ Mass per unit area $\left(\mathrm{g} / \mathrm{m}^{2}\right)$} & \multicolumn{2}{|c|}{275} \\
\hline \multicolumn{2}{|c|}{ Density (threads/10 cm) } & 270 & 220 \\
\hline \multirow{2}{*}{ Breaking force } & $F(N)$ & 1.386 & 1.072 \\
\hline & CV (\%) & 4.3 & 5.2 \\
\hline \multirow{2}{*}{ Elongation at break } & $\varepsilon(\%)$ & 52.4 & 48.4 \\
\hline & CV (\%) & 4.8 & 6.2 \\
\hline
\end{tabular}

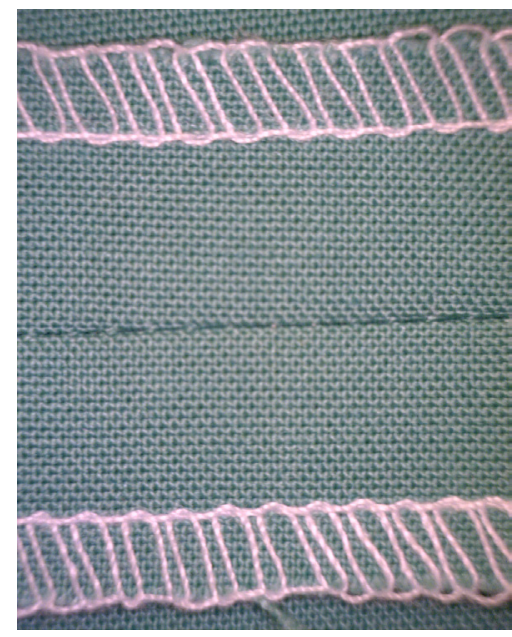

(a)

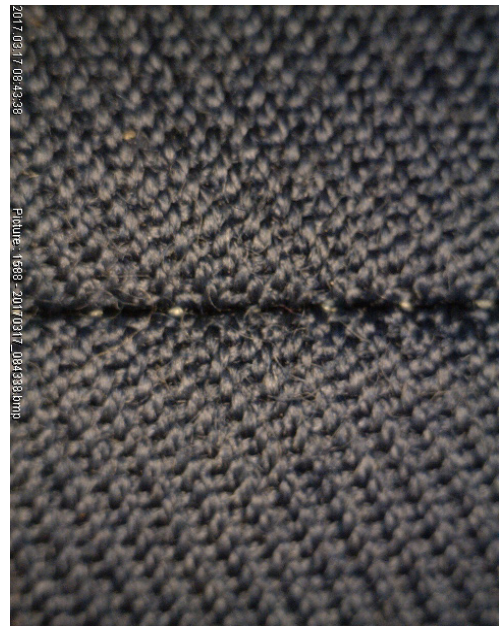

(b)

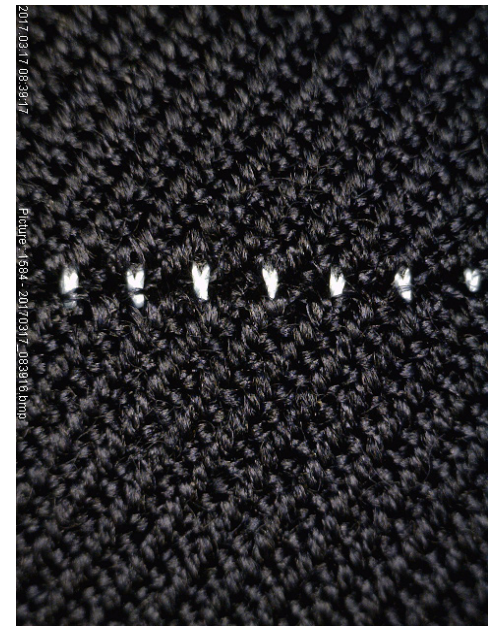

(c)

Figure 3. (a) By sawn seam joined woven fabric, (b) enlarged view of the joined place and sewn seam without loading, (c) enlarged view of the joined place and sewn seam with loading

Table 2. Calculated values of applied preloading

\begin{tabular}{|c|c|c|c|c|}
\hline & $\begin{array}{c}\text { Average } \varepsilon \% \text { (sample tested } \\
\text { without additional preload) }\end{array}$ & $\begin{array}{c}\text { Additional preload of } \\
\boldsymbol{\varepsilon} \mathbf{3 0 \%}\end{array}$ & $\begin{array}{c}\text { Additional preload of } \\
\boldsymbol{8} \mathbf{5 0} \%\end{array}$ & $\begin{array}{c}\text { Additional preload of } \\
\boldsymbol{\varepsilon} \mathbf{7 0} \%\end{array}$ \\
\hline$\varepsilon(\%)$ & 14.34 & 4.30 & 7.17 & 10.00 \\
\hline
\end{tabular}

parts with sewn seam, breaking properties of the material is greatly reduced. As shown in Figure 4 and Table 1, breaking force is reduced to even $71.08 \%$ (from $1.072 \mathrm{~N}$ of sample without seam to $310 \mathrm{~N}$ of sample with seam) and elongation at break is reduced to $70.37 \%$ (from $48.40 \%$ of sample without seam to $14.34 \%$ of sample with seam).

As already mentioned, additional preload was defined by a certain percentage of the average elongation at break of the sample tested without additional preload, and the specific values are given in Table 2.

Applying a preloading, in which the tested samples were remained for $3 \mathrm{~h}$, greatly changes the fabric properties. As a result of the preload application, it would be expected that the fabric experience further degradation and that breaking properties further reduce, but, however, exactly the opposite thing occurred. Breaking properties are increased even more with every preload (Figure 4).

With additional preload of $30 \%$, increase of breaking force of $3.77 \%$ and elongation at break of $2.30 \%$ was noted, in relation to the sample tested without preload. With additional preload of $50 \%$, in relation to the sample tested without preload, increase of breaking force of $4.19 \%$ and elongation at break of $3.84 \%$ was recorded; and with additional preload of $70 \%$, in relation to the sample tested without preload, increase of breaking force of $8.47 \%$ and elongation at break of $9.83 \%$ was recorded. 


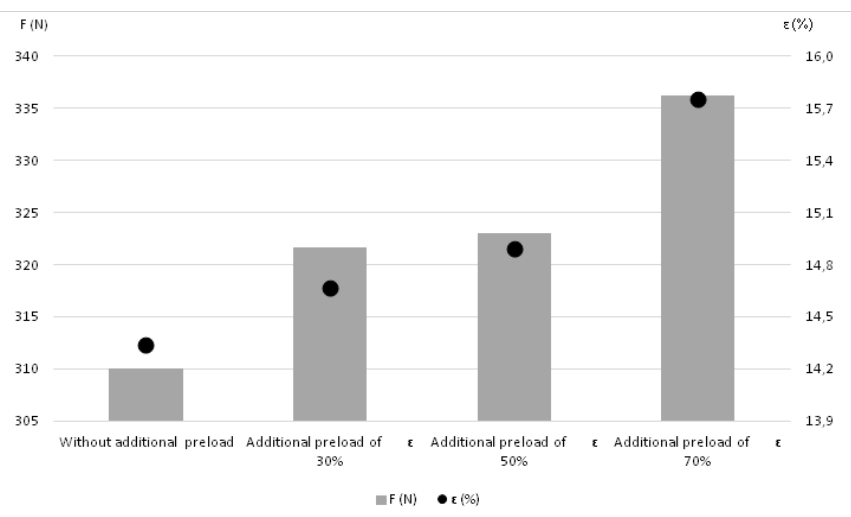

Figure 4. Breaking properties (breaking force $\mathrm{F}(\mathrm{N})$ and elongation at break $\varepsilon(\%)$ of sewn samples without additional preload and with additional preload of $\varepsilon 30 \%, 50 \%$ and $70 \%$

The reason for such an increase can be found in woolen fibers, that is, their properties (which are characterized by extremely high elongation of $25-50 \%$ ) and their behavior within the yarn, where under load occurs strong friction caused by the scaly fiber surface, which prevents the fibers slippage, allowing fibers to be restructured within the yarn, thus retaining and increasing its elongation properties.

It is interesting to analyze the distribution of force to break on samples tested with applying preload (Figure 5). For the applied preload of $30 \%$ of $\varepsilon$, the force of $42.33 \mathrm{~N}$ was used, or $13.16 \%$ of the total force to break, which means that after remaining in the preload position for $3 \mathrm{~h}$, additional force of $279.34 \mathrm{~N}$ was required in order to achieve break occurrence. To achieve the preload of $50 \%$ of $\varepsilon$, the force of $143.00 \mathrm{~N}$ was required, that is, $44.27 \%$ of total force needed for breakage. For preload of $70 \%$ of $\varepsilon$, even $72.86 \%$ of total force was used, which means that the force of only $91.25 \mathrm{~N}$ was needed for fabric breakage occurrence.

The overall increase in elongation at break at samples with applied preload compared to samples without preload was established earlier. Therefore, the real value of elongation at the moment of achieving needed preload $(30 \%, 50 \%$ and $70 \%$ of elongation at break of sample without preloading) and $3 \mathrm{~h}$ inaction, considering the total values of elongation at break of individual test samples, is as follows: $29.31 \%$ for sample with applied preload of $30 \%, 48.15 \%$ for sample with applied preload of $50 \%$, and $63.49 \%$ for sample with applied preload of $70 \%$ (Figure 6 ).

It is important to note once again that these values of conducted tests are the result of properties of woolen fibers, which have the strong ability to elastically recover deformation after loading (e.g., after fiber stretching for $2 \%$ deformation return is almost complete (95-99\%); at elongation of 5\%, elastic deformation is $60-70 \%$, and after $10 \%$ elongation, elastic recovery is $40-50 \%$ ) [15], which is also transmitted to the properties of the fabric.

Although the application of additional preload of samples (30\%, $50 \%$ and $70 \%$ of the average elongation at break) for a period of 3 $\mathrm{h}$ does not cause reduction of fabric breaking properties, a different kind of material deformation occurs precisely at the joint places, which affects the appearance and quality of the final product.

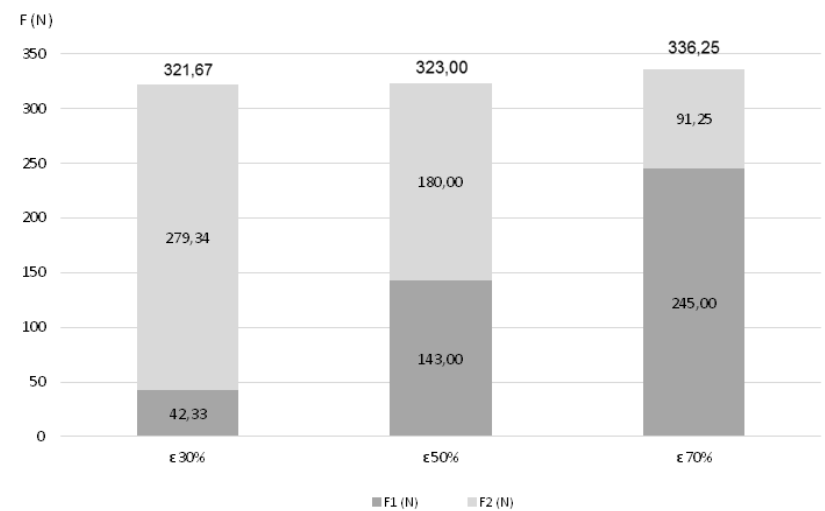

Figure 5. Force distribution to break ( $\mathrm{F} 1(\mathrm{~N})$, force to preload; F2 $(\mathrm{N})$, force after preload to break)

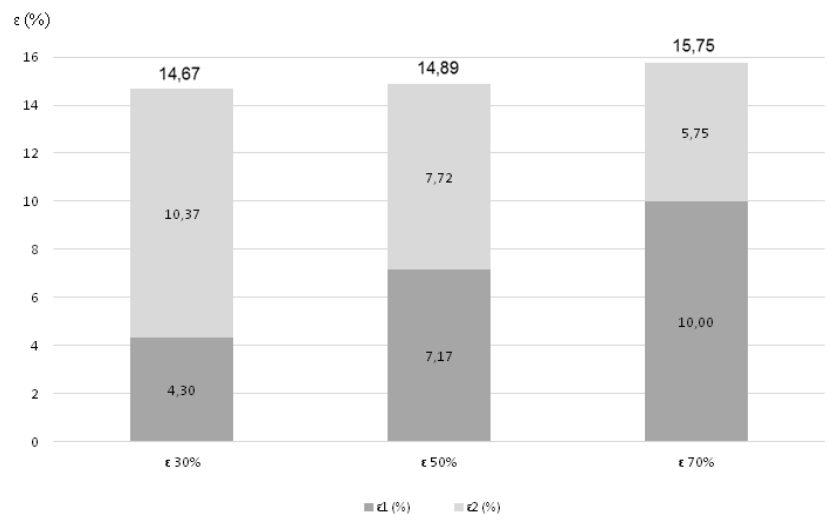

Figure 6. Elongation distribution to break ( $\varepsilon 1(\%)$, elongation to preload; $\varepsilon 2(\%)$, elongation after preload to break)

Such deformation are caused by the properties of the raw material (characteristics of wool), where because of the fabric elongation, no destruction on the fabric level occurs, but changes on the yarn level, that with its specific properties provides fibers restructuring within the yarn, resulting in an additional elongation and yarn convergence, which is reflected in folding of the material (Figure 3).

\section{Conclusions}

As seams are mostly in folds and locations with the highest deformations, quality significance, durability, and appearance of seams are of paramount importance for each garment. This type of clothing (suit) should be made of high-quality fabrics to fit well on the garment, to match in size and pattern, to drape well, and not to crease. Fabrics with these characteristics are often made of wool and PES and belong to medium weight fabrics. Such clothing under the condition in use is often subjected to great stresses, which are mostly present in the area of joint places, where longer and larger loading causes deformations, especially in those weakest areas of sewn seam.

To minimize the deformations of the fabric in the seams and to keep the seam strong and durable as long as possible, it is necessary to select an appropriate sewing thread, stitch length, and also other parameters such as needle characteristics, thread tension, and stitch type. Furthermore, structural fabric parameters affect the behavior of material such as its density, 
weft and warp fineness, weave type, fabric mass per unit area, and, what in this case had the greatest influence, raw material composition. These structural parameters, beside thread and seam parameters, also have an impact on thread slippage in the sewing seam caused by stress during wearing the garment, while during longer and greater loads, it can lead to its weakening or breakage. Therefore, quality and durability of the clothing item is mostly limited with properties, that is, durability and quality of woven fabric and seam.

\section{Acknowledgments}

The financial support was provided within the framework Support scientific research 2017 "Natural Fibres Agrotextile" (TP 12/17), financed by the University of Zagreb.

\section{References}

[1] Bharani, M., Shiyamaladevi, P.S.S., Mahendra Gowda, R.V. (2012). Characterization of Seam Strength and Seam Slippage on Cotton Fabric with Woven Structures and Finish. Research Journal of Engineering Sciences, 1, 4150.

[2] Thanaa Moustaf AL Sarhan. (2013). Interaction between Sewing Thread Size and Stitch Density and Its Effects on the Seam Quality of Wool Fabrics. Journal of Applied Sciences Research, 9(8), 4548-4557.

[3] Mandal S, Theses, Institute of Textiles \& Clothing, The Hong Kong Polytechnic University, 2008.

[4] Germanova-Krasteva, D., Petrov, H., (2008). Investigation on the seam's quality by sewing of light fabrics. International Journal of Clothing Science and Technology, 20 (1), 57-64.
[5] Gribaa, S., Amar, S.B., Dogui, A., (2006). Influence of sewing parameters, upon the Tensile behavior of textile assembly. International Journal of Clothing Science and Technology, 18 (4), 235-246.

[6] Nassif, N. A. A. (2013). Investigation of the effect of sewing machine parameters on the seam quality. Life Science Journal, 10(2), 1427-1435.

[7] Abdul Ghani S., (2011). Seam performance: Analysis and Modelling. Thesis, Manchester, UK: The University of Manchester.

[8] LaPere C., (2006). The Effects of Different Fabric Types and Seam Designs on the Seams [sic] Efficiency. Senior Honors Theses. 53., Eastern Michigan University.

[9] Barbulov - Popov, D., Cirkovic, N, Stepanović, J., (2012). The Influence of Stitch Density and of the Type of Sewing Thread on Seam Strength. TEM Journal, 1 (2), 104-110.

[10] Jucienë, M., Vobolis, J., (2006). Investigation of Stitch Length Change under the Conditions of Sweding Garment Inertia Motion. Tekstil, 55 (5), 244-248.

[11] Ujević, D., Kovačević, S., Horvat Varga, S., (2011). Analysis of High-Frequency Artificial Leather Welding as a Function of Seam Quality. Fibres \& textiles in Eastern Europe. 19, 4 (87), 94-100.

[12] Ujević, D., Kovačević, S., Wadsworth, L.C., Schwarz, I., Brlobašić Šajatović, B. (2009). Analysis of artificial leather with textile fabric on the backside. Journal of textile and apparel technology and management. 6 (2), 1-9.

[13] Geršak, J., (2001). Directions of sewing technique and clothing engineering development (in Croatian). Tekstil, 50 (5), 221-229.

[14] Vobolis, J., Jucienë, M., (2003). Estimation of Fabrics Dynamical Stiffness and Damping in Sewing Garments. Tekstil 52 (4), 160-165.

[15] Čunko, R., Andrassy, M., (2005). Vlakna, Zrinski, Čakovec, ISBN: 953-155-089-1. 